\title{
Decreasing Anastomotic Leakage Rate Following Preoperative Radiotherapy and Low Anterior Resection for Rectal Cancer: Reply
}

\author{
Jin Gu $\cdot$ Lin Wang
}

Published online: 5 October 2010

(c) Société Internationale de Chirurgie 2010

We are grateful to Dr. Hottenrott for his comments. In his letter he focused on the indications for preoperative radiotherapy of locally advanced rectal cancer, the value of defunctioning the stoma, and the influence of total mesorectal excision (TME) on the leakage rate. The metaanalyses [1] indicated that preoperative radiotherapy at a biological equivalent dose (BED) $\geq 30$ Gy could significantly reduce the local recurrence rate. As reported in the Dutch TME trial [2], short-course preoperative radiotherapy could reduce the risk of local recurrence in rectal cancer patients who underwent a standardized TME. In our retrospective research [3], the adoption of preoperative radiotherapy was based on prestaging by endorectal ultrasonography or magnetic resonance imaging. Only T3+ or any $\mathrm{T} / \mathrm{N}+$ cases were irradiated. The BED of a $30 \mathrm{~Gy} / 10 \mathrm{f}$ regimen was $36 \mathrm{~Gy}$.

The TME performed was the standardized technique for mid-low rectal cancer in our unit. Comparable to other leakage risk factors, TME itself is a risk factor that reduces the blood supply to the rectum stump [4]. However, it is difficult to conduct a trial to compare TME and conventional surgery because non-TME surgery would be ethically unacceptable.

Although the defunctioning stoma may reduce the anastomotic leakage and contribute to faster healing, the results from several randomized controlled trials (RCTs) of preoperative radiotherapy were unable to define whether a protective stoma could reduce the leakage rate. As reported by Marijnen et al. [5], the percentage of low anterior resection patients who exhibited clinical leakage was not statistically

J. Gu $\cdot$ L. Wang $(\bowtie)$

Department of Colorectal Surgery, Peking University School of Oncology, Beijing 100026, China

e-mail: zlwanglin@yahoo.com.cn different for preirradiated and non-preirradiated patients (11 vs. $12 \%, P>0.05)$. However, the proportion of protective stoma in the irradiation group or the control group was not comparable in this RCT (60 vs. $53 \%, P=0.05$ ) [2, 5]. Second, most surgeons are prone to allow more protective stomas in irradiated patients than in nonirradiated patients [6]. Moreover, in a recent RCT ( $n=234,79 \%$ preirradiated, $25 \mathrm{~Gy} / 5 \mathrm{f})$, Matthiessen et al. [7] proved that a protective stoma could decrease the leakage rate. It seems evident that a protective stoma is indispensible in patients who undergo preoperative radiotherapy and low anterior resection.

\section{References}

1. Colorectal Cancer Collaborative Group (2001) Adjuvant radiotherapy for rectal cancer: a systematic overview of 8,507 patients from 22 randomised trials. Lancet 358:1291-1304

2. Kapiteijn E, Marijnen CA, Nagtegaal ID et al (2001) Preoperative radiotherapy combined with total mesorectal excision for resectable rectal cancer. N Engl J Med 345:638-646

3. Wang L, Gu J (2010) Risk factors for symptomatic anastomotic leakage after low anterior resection for rectal cancer with $30 \mathrm{~Gy} /$ $10 \mathrm{f} / 2 \mathrm{w}$ preoperative radiotherapy. World J Surg 34:1080-1085

4. Vignali A, Gianotti L, Braga M et al (2000) Altered microperfusion at the rectal stump is predictive for rectal anastomotic leak. Dis Colon Rectum 43:76-82

5. Marijnen CA, Kapiteijn E, van de Velde CJ et al (2002) Acute side effects and complications after short-term preoperative radiotherapy combined with total mesorectal excision in primary rectal cancer: report of a multicenter randomized trial. J Clin Oncol 20:817-825

6. Peeters KC, Tollenaar RA, Marijnen CA et al (2005) Risk factors for anastomotic failure after total mesorectal excision of rectal cancer. Br J Surg 92:211-216

7. Matthiessen P, Hallböök O, Rutegård J et al (2007) Defunctioning stoma reduces symptomatic anastomotic leakage after low anterior resection of the rectum for cancer: a randomized multicenter trial. Ann Surg 246:207-214 